\title{
Narrar histórias para se constituir educador ambiental pela pesquisa
}

\author{
Maria do Carmo Galiazzi ${ }^{1}$, Alessandra Viveiro, Ângela Maria Zanon, \\ Angélica Góis Müller Morales, Daniela Gonçalves de Abreu, Edna Ferreira \\ Costa do Sim, Felipa Pacifico Ribeiro de Assis Silveira, Márcia Vieira Silva, \\ Nazaré Araújo da Fonseca, Sônia Maria Marchiorato
}

\section{Introdução}

O Programa de Pós-Graduação em Educação Ambiental da FURG tem, ao longo dos últimos anos, investido na pesquisa como princípio educativo (DEMO, 1997; GALIAZZI, 2003) da formação de educadores ambientais pesquisadores. Este texto apresenta-se nessa perspectiva e a ela se agrega a pesquisa narrativa como elemento transformador da realidade da formação de educadores ambientais. Nesse sentido, a narrativa está sendo pensada como eixo articulador de diferentes atividades e como processo de reflexão sobre a própria constituição do educador ambiental, pretendendo-se

\footnotetext{
1 Professora do Programa de Educação Ambiental da FURG, convidada pelos organizadores do IV EPEA (Encontro de Pesquisa em Educação Ambiental) para organizar um grupo de estudos sobre a constituição de educadores ambientais. Contato: mcgaliazzi@yahoo.com.br Foram convidados a participar do GDP e posteriormente a esta produção coletiva os seguintes participantes, além das autoras: Alessandra Viveiro, Ana Paula Carriati, Ana Odalia Vieira Sena, André Rangel Nascimento, Angela Maria Hartmann, Arthur Henrique de Oliveira, Bárbara Suleiman de Macedo, Bruna Monize Rosalem, Cathia Alves, Daniela Gonçalves de Abreu, Daniela Harumi Hikawa, Edna Ferreira Costa do Sim, Fábio Alves Leite da Silva, Fernanda Freitas Paiva, Flávia Nascimento Ribeiro, Genoveva Chagas de Azevedo, Helena Maria da Silva Santos, Heloisa Gaspar, Jorge Sobral S. Maia, Joselita Modesto Cordeiro, Juliana Rink, Karina Maretti Strangueto, Leandro Sadao Mizuno, Leni Bueno, Leonir Lorenzetti, Mara Rejane Osório Dutra, Márcia Vieira Silva, Maria Inêz Oliveira, Marilu Mercadante, Roberta Moreira de Souza, Rosana Louro Ferreira Silva, Rosmari Lazarini, Silvia Aparecida Martins dos Santos, Simone Portugal, Simone Sendin Moreira, Sônia Maria Marchiorato, Thaís Gimenez da Silva Augusto e Thales Righi.
} 
estabelecer um programa de pesquisa em comunidades de aprendizagem com os alunos, mestrandos e doutorandos do PPGEA.

A primeira autora, ao ser convidada a coordenar um grupo de discussão - GDP - sobre pesquisa na formação de educadores ambientais no IV EPEA - Encontro de Pesquisa em Educação Ambiental, propôs o GDP como o desenvolvimento de um exercício de pesquisa narrativa.

Por isso, o texto aqui apresentado é a aposta de uma possibilidade da narrativa como constituidora de educadores ambientais. Para realizá-la, utilizamos especialmente o ambiente virtual como ferramenta de produção de significados dessas histórias (www.ceamecim.furg.br/avatool2/2). Os relatos foram produzidos pelos participantes no IV EPEA - GDP Formação de Educadores Ambientais, realizado em Rio Claro-SP, de 15 a 18 de julho de 2007.

Neste trabalho, apresentamos inicialmente os princípios da pesquisa narrativa permeados pelas intenções postas, assumidas pelo grupo de participantes e desenvolvidas durante o GDP. Foi assim que o texto foi se acrescentando de autores que produziram relatos, leram e interferiram nele. Todos os participantes contribuíram para que se alcançasse este resultado, porém, aqueles que não se inscreveram no ambiente virtual não puderam ser nomeados.

\section{Princípios da pesquisa narrativa}

A pesquisa narrativa tem sua aplicação em diferentes campos do conhecimento, em especial na área da Educação, e diferentes abordagens de pesquisa. Para pesquisadores narrativos, o mundo pode ser entendido e estudado de forma narrativa, tendo a experiência das pessoas como ponto central, porque o pensamento narrativo é uma forma fundamental de experiência e também uma forma de escrever e refletir sobre ela. A narrativa é o fenômeno estudado, assim como o método de estudá-lo (CLANDININ; CONNELLY, 2000). Como afirma Bruner (2003), estamos o tempo todo

\footnotetext{
2 Para ver o conteúdo desta discussão é preciso deste entrar em gdp ivepea e solicitar cadastro.
} 
ouvindo narrativas, contando-as como as compreendemos - verdadeiras ou falsas, reais ou tendo sentido, acusações ou escusas.

E é nesse movimento que as consideramos e estamos adaptados a elas de tal forma que nos parecem quase tão naturais quanto a linguagem. Por isso, o autor afirma que uma narrativa não pode ser explicada. Tudo o que se pode fazer com ela é interpretá-la de diferentes e variadas formas (BRUNER, 2001).

Alguns aspectos são importantes para a pesquisa narrativa. A temporalidade é um deles e está vinculada ao fato de que uma experiência ocorre em determinado tempo e espaço, relacionando-se com o contexto mais amplo em que o indivíduo vive. Tendo em vista que se vive a vida em um contínuo, considera-se que o significado da experiência pode ser modificado com o tempo. Assim é que Bruner (2001) argumenta que uma narrativa segmenta o tempo pelo desencadeamento de eventos que ele denomina de cruciais. Quem atribui importância a esses eventos é o narrador.

Os episódios ou eventos cruciais que marcam a produção deste artigo podem, portanto, ser assim demarcados:

1. convite para a coordenação do evento;

2. desenvolvimento do ambiente virtual de aprendizagem;

3. aceitação da proposta pelos participantes;

4. realização do GDP no IV EPEA;

5. produção do texto coletivo via ambiente virtual.

Para nós, a experiência foi considerada desde o momento em que escrevemos nossas histórias no ambiente virtual; depois, nos encontramos presencialmente no IV EPEA e posteriormente produzimos este artigo, com histórias semelhantes de grupos de participantes.

Mas como significamos experiência? Experiência é a vivência refletida. É na experiência que ocorrem as aprendizagens. E é com Larrosa (2002, p. 24) que podemos afirmar que é preciso dar à experiência um sentido diferente daquele que lhe é comumente atribuído pela ciência moderna. Como assinalou o referido autor:

A experiência, a possibilidade de que algo nos aconteça ou nos toque, requer um gesto de interrupção, um gesto que é quase impossível nos tempos que correm: 
requer parar para pensar, parar para olhar, parar para escutar, pensar mais devagar, olhar mais devagar, e escutar mais devagar; parar para sentir, sentir mais devagar, demorar-se nos detalhes, suspender a opinião, suspender o juízo, suspender a vontade, suspender o automatismo da ação, cultivar a atenção e a delicadeza, abrir os olhos e os ouvidos, falar sobre o que nos acontece, aprender a lentidão, escutar aos [sic] outros, cultivar a arte do encontro, calar muito, ter paciência e dar-se tempo e espaço.

Com esse sentido dado à experiência, a continuidade também caracteriza a pesquisa narrativa. Uma história deve ser vista nesse contínuo, sendo transformada e transformando, precisa ser olhada em termos de passado (movimento para trás, quando cada um dos participantes narra de que forma se constituiu educador ambiental), de presente (que pode ter sido o encontro presencial, como pode ser este momento agora de leitura em que se agrega à experiência o leitor), de futuro (movimento para frente, como cada um vai produzindo a partir do experenciado, transformações em seus contextos de atuação profissional, incorporando experiências em suas ações) e se compõe ainda de significados pessoais (movimento para dentro) e sociais (movimento para fora). Passado, presente e futuro são pensados de forma simultânea na interpretação de uma narrativa. Por meio desta, afirma Bruner (2003), nós construímos e reconstruímos e, de certa forma, reinventamos o ontem e o amanhã. Ou seja, não é uma única história que se conta. O enredo, os personagens e o contexto continuam e se expandem.

Importante na perspectiva assumida da pesquisa narrativa é a inclusão do pesquisador como um narrador, como participante nas histórias relatadas e interpretadas, assimilando assim a idéia de transformação, de mudanças - no mundo, na pesquisa, nele mesmo - e da atitude dele para com os participantes, buscando a promoção da aprendizagem sobre o fenômeno estudado. No caso dos autores deste texto, somos todos narradores e sujeitos de experiência, como propõe Larrosa (2002, p. 24-25):

O sujeito da experiência é um sujeito ex-posto. Do ponto de vista da experiência, o importante não é nem a posição (nossa maneira de pormos), nem a o-posição (nossa maneira de opormos), nem a im-posição (nossa maneira de impormos), 
nem a pro-posição (nossa maneira de propormos), mas a ex-posição, nossa maneira de ex-pormos, como tudo o que isso tem de vulnerabilidade e de risco. Por isso é incapaz de experiência aquele que se põe, ou se opõe, ou se impõe, ou se propõe, mas não se ex-põe. É incapaz de experiência aquele a quem nada the passa, a quem nada lhe acontece, a quem nada lhe sucede, a quem nada o toca, nada lhe chega, nada o afeta, a quem nada o ameaça, a quem nada ocorre.

É por isso que, quando pensamos na pesquisa narrativa como modo de produção de conhecimento, encontram-se pontos de tensão: o lugar da teoria, a quantidade de teoria suficiente para embasar o trabalho acadêmico, o lugar das pessoas e o do pesquisador no desenvolvimento da pesquisa. $\mathrm{Na}$ pesquisa narrativa, o formalismo e o reducionismo não desejados podem se fazer presentes, colocando a narrativa e a experiência em descrédito pelos pesquisadores formalistas e tradicionais ou pelos mais ortodoxos. Mas, como dito, apresentar uma experiência é ex-por-se ao vulnerável e ao risco de interpretações e tudo isso depende de onde nos observam.

Clandinin e Connelly (2000) criticam o mito da forma da pesquisa formalista, na qual nos tornamos prisioneiros de formas, teorias, expectativas, experiências passadas e nossa linguagem, em que as coisas não são o que são, mas aquilo que o paradigma ou a perspectiva fazem delas. A pesquisa narrativa é vista então com suspeita porque propõe reconstruir a experiência de uma pessoa em relação a outras e a um contexto. Ao contrário, o que querem os pesquisadores narrativos é o sentido de experiência indo ao encontro do sentido dado a ela pela ciência moderna, como posto por Larrosa (2002, p. 28):

[...] o saber da experiência pretende evitar a confusão de experiência com experimento ou, se se quiser, limpar a palavra experiência de suas contaminações empíricas e experimentais, de suas conotações metodológicas e metodologizantes. Se o experimento é genérico, a experiência é singular. Se a lógica do experimento produz acordo, consenso ou homogeneidade entre os sujeitos, a lógica da experiência produz diferença, heterogeneidade e pluralidade. ... Se o experimento é repetível, a experiência é irrepetível, sempre há algo como a primeira vez. Se o experimento é preditível e previsível, a experiência tem sempre uma dimensão de incerteza que não pode ser reduzida. Além disso, posto que 
não se pode antecipar o resultado, a experiência não é o caminho até um objetivo previsto, até uma meta que se conhece de antemão, mas é uma abertura para o desconhecido, para o que não se pode antecipar nem pré-ver nem pré-dizer.

Ao contrário da pesquisa formal, que é iniciada pela teoria, a pesquisa narrativa começa com os relatos, para que possam transformar-se em experiência. É por isso que a teoria na pesquisa narrativa é vista com os óculos da experiência, que vem em primeiro plano, e com ela se entrelaça, mas não se sobrepõe a ela. As pessoas que participam da pesquisa narrativa são vistas como constituidores de histórias através das quais também se constituem. São pessoas pertencentes a uma classe, raça ou gênero, porém, o foco da pesquisa está na pessoa em si e na sua experiência pessoal, não nesse pertencimento. $O$ pesquisador precisa estar consciente do entrelaçamento e influência de suas histórias pessoais no trabalho que está desenvolvendo. Os relatos aqui considerados foram os relatos individuais feitos primeiramente no ambiente virtual de aprendizagem e posteriormente no primeiro momento do encontro. Trazemos um deles como exemplo:

\section{Começando a conversa!}

Desde 2000 eu tenho trabalhado com EA. A caminhada começou na graduação quando desenvolvemos algumas pesquisas na área ambiental. Logo em seguida, acabei encontrando pessoas de uma ONG ambientalista e a caminhada com a EA começou. Fui coordenadora de EA na Prefeitura de Pelotas, onde organizamos diferentes experiências com EA (em escolas, comunidades...). No processo fui fazer mestrado na Faculdade de Educação..., linha de pesquisa currículo, formação e trabalho docente, tive oportunidade de desenvolver a pesquisa "Professores e EA: uma relação produtiva".

$\mathrm{O}$ estudo teve como enfoque a relação dos professores com a Educação Ambiental (EA). Assim, a partir da análise de um conjunto de discursos que foram utilizados por professores de escolas municipais, mostrei que as representações sobre as práticas de EA desses professores tiveram efeitos produtivos no espaço escolar. Olhei para os discursos dos professores numa perspectiva pós-estruturalista, que me ajudou a argumentar que os discursos dos 
professores e as condições que as escolas proporcionam à EA produzem um tipo específico de EA. Percebi, nestas escolas, um tipo de EA marcada por um currículo turístico, por práticas pedagógicas que reduzem a problemática ambiental a procedimentos pontuais de embelezamento e limpeza do ambiente e pelo desejo de produzir um sujeito auto-reflexivo, autogovernado e consciente dos problemas ambientais. Argumentei, ainda, que os discursos dos professores sobre a EA foram marcados e influenciados por diferentes discursos que os interpelam. Dois deles foram fundamentais: governo local, no papel da secretaria de meio-ambiente, e os temas transversais.

Atualmente, sou doutoranda do mesmo PPGE, e estou estudando EA e políticas oficiais de formação de professores. Agora quero saber como o MEC produz as políticas de formação para EA e o que os discursos que constituem essas políticas dizem sobre o educador ambiental.

Neste caminho, muita aprendizagem, desconstrução e construção de uma educadora ambiental. Outros olhares, muita desconfiança e muito prazer por estar neste caminho.

Na pesquisa narrativa, vive-se a experiência sobre a qual se estuda, em uma perspectiva historiada de ver a vida e o mundo. Anotar ou ouvir histórias, registrar fazeres, ações e acontecimentos referentes ao contexto estudado são caminhos a serem percorridos pelo pesquisador. Nesse tipo de pesquisa, o pesquisador precisa ficar completamente envolvido, apaixonado pelo trabalho com os participantes, mas deve alternar proximidade e distanciamento para construir seus textos de campo. A composição desses textos depende de registros interpretativos adequados do que foi vivenciado, não deixando sua construção por conta da memória.

Os textos de campo podem ser de vários tipos, como anotações de campo, entrevistas, diário do pesquisador, cartas, diálogos, etc., e precisam ser rigorosamente desenvolvidos e ricamente detalhados. Como são essencialmente interpretativos, podem falar sobre o que é ou não dito e/ou observado, dependendo do que o pesquisador consegue focalizar ou das opções que faz. Esses textos podem ser moldados na relação entre o pesquisador e o entrevistado, porque se constroem no processo de relacionamento entre eles, e contextualizados, em função das circunstâncias de ocorrência da entrevista. Possibilitam um recontar da 
história vivida, abrindo um espaço para reflexão, mudança e transformação, permitindo crescimento contínuo.

$\mathrm{O}$ pesquisador narrativo deve começar situando-se como participante da pesquisa, e pode fazê-lo contando suas próprias experiências, que podem ser autobiográficas. Estas últimas permitem ao pesquisador refletir sobre si mesmo e sobre os objetivos da pesquisa quanto ao tema, para que tenha consciência da escolha e da sua relevância no sentido pessoal e profissional. A justificativa pessoal é encorajada e se entrelaça com a justificativa social, que a engloba e transcende. É por isso que começamos com nossos relatos individuais, trazendo fragmentos de alguns deles:

\section{Buscando caminhos: uma miniexperiência ambiental}

Posso dizer que minha experiência ambiental começou, mesmo, quando criança, com meus pais. Eles adoravam plantas, árvores frutíferas, tudo que fizesse parte deste mundo da natureza. Meu pai vivia fazendo enxerto nas árvores frutíferas do nosso sítio e eu caminhando junto. Minha mãe tinha coleção de avencas, rosas e outras plantas. Ao abrirmos a janela que dava para o quintal, víamos um espetáculo maravilhoso. Uma verdadeira pintura realizada pela natureza. Ela tinha uma espécie de papoula que nunca abria. Era eternamente botão. Nossa sala de café dava para o jardim onde este pé de papoula estava plantado. Por ser botão, o beija-flor vinha tirar o néctar, logo, nosso café era um festival destes pássaros voando ao redor da planta e você pode deduzir como era linda nossa hora do café da manhã.

$\mathrm{Na}$ época, não tinha noção da maravilha que era tudo isto. E que este espetáculo pudesse, um dia, deixar de existir.

Atualmente, principalmente agora, estas lembranças vêm com uma cor muito viva. Mesmo morando em apartamento, não deixo de ter meus pássaros na janela e minhas avencas pela sala. Minha região e minha cidade oportunizam esta vivência.

$\mathrm{Na}$ minha função de Pedagoga continuo buscando caminhos para que toda a sensibilidade criada, desenvolvida em mim, não se perca.

$\mathrm{Na}$ escola de aplicação da UFPA, além do trabalho interno, que ainda tem bastante resistência, estamos desenvolvendo projetos com o pessoal ribeirinho, que é minha paixão. O pessoal começou com oficinas dentro da realidade deles, mas, sou daquelas que gosta de colocar a mão na massa e vi que primeiro havia necessidade de informação, depois de ação. O produto melhorou bastante. 
Sou voluntária em uma escola pública em um bairro barra-pesada, periferia mesmo. Nosso trabalho é integração escola x comunidade. Solicitamos aos comerciantes que adotassem uma local do bairro e fizemos a revitalização do logradouro. Você já deve estar sentindo a veia da minha mãe. Plantar árvores, flores, plantas de nossa região. Para que isso aconteça temos que trabalhar a limpeza. Tem muita coisa a ser feita. Nossa busca é para que não haja desvirtuação da Educação ambiental. Ela não é algo somente, transversal. Ela é algo fundamental em nossas vidas. Necessitamos investir na formação do educador ambiental para que ele não seja um professor pontual das datas ambientais.

È difícil, mas, não impossível. A visão de Educação Ambiental para um lado e meio ambiente para outro ainda é muito arraigada. Nosso trabalho está na fase de cartilhas, folder, parcerias, ou seja, na fase informativa. Vamos fazer concursos para dar nomes aos ícones representativos das atividades. Os alunos trabalham bastante, afinal eles têm muito a nos ensinar.

Neste IV EPEA tenho certeza de que trarei muitas experiências maravilhosas para somar com as nossas, daqui.

Vamos fazer desta frase, por sinal muito feliz, nosso lema: "Feliz daquele que transfere o que sabe e aprende o que ensina" (Cora Coralina).

Os textos de pesquisa surgem a partir dos textos de campo e alguns aspectos devem ser considerados de forma cuidadosa: voz, autoria, forma narrativa e audiência, desafios sempre presentes quando são construídos. Esse processo, para pesquisadores iniciantes, é permeado por tensões/conflitos, internos e/ou externos, como, por exemplo, em determinado momento ter que se afastar do campo empírico, ou ainda, o que fazer com o conjunto de textos de campo e como decidir para quem escrever e a forma de comunicar, escolher, entre várias, uma possibilidade de capturar as vozes, e outros. Nesse sentido é que este texto começou com a primeira autora em sua primeira versão e é agora apresentado incorporando um conjunto de autores que, a partir da proposição, estiveram juntos fazendo experiência formativa, enfatizando que a experiência é essencialmente formativa e produtora.

A forma de reapresentar esses textos precisa considerar os participantes, expressar suas vozes e o contexto estudado, ser coerente na maneira de apresentação em relação ao tema de estudo. Deve evitar a 
possibilidade de redução factual (a interpretação de um fato passa a ser uma verdade, o que aqui evitamos) e também generalizar experiências individuais como se pudessem ser de todos ("os educadores ambientais são amantes da natureza"). Como exemplo disso, trazemos uma história produzida pelos participantes do grupo do GDP "Os determinados", no qual se manteve entre eles, com a intenção de mostrar os autores nos sentidos produzidos, o que incluiu a decisão pela forma do texto produzido coletivamente:

\section{Grupo: DETERMINAÇÃO}

* Como nós nos constituímos como educadoras ambientais?

Nos reconhecemos como educadoras ambientais determinadas e diante das narrativas encontramos alguns pontos comuns, como:

Todas possuem formação em licenciatura nas áreas de Biologia e Geografia e também buscam por uma formação continuada, por meio de cursos de lato e stricto sensu e outros.

A maioria possui vínculo afetivo às questões ambientais (influência familiar); sensibilidade natural.

Vontade de ser educadoras foi um fator que uniu todas as narrativas no enfoque da educação formal e não-formal.

Nós também nos deparamos numa "zona de desconforto" em algum momento de nossa formação acadêmica ou trajetória profissional, o que possibilitou a busca pela EA, por questões sociais, etc.

Todas as educadoras ambientais tiveram contato "formal" com a EA na própria academia. Por sua vez, reconhecemos a importância do ensino superior (academia) no processo de formação em educação ambiental.

Observação: É muito interessante discutirmos a importância da ênfase da EA nos cursos de formação inicial e continuada.

Esse texto tem que ser situado considerando que a paisagem estudada deve ser vista em movimento, se transformando, além de ter que encontrar o caminho para transformar os significados das experiências estudadas em texto, considerando o espaço tridimensional da pesquisa narrativa. O texto, nesse sentido, vai se transformando em uma ferramenta produtiva. Ou seja, o leitor reflete sobre sua constituição enquanto 
educador ambiental e por ele (o texto) se constitui. E então como foi produzido esse texto? A partir de diálogos propostos em um ambiente virtual, produzimos narrativas individuais sobre como fomos nos constituindo educadores ambientais. No GDP, aproximamos histórias e constituímos grupos que sintetizaram essas histórias.

O pesquisador tem que exprimir as múltiplas vozes expressas em seu texto de pesquisa, pertencentes a si e aos participantes, assim como seu texto deve falar para e refletir as vozes da audiência. As vozes silenciadas precisam ser consideradas, visto que o silêncio escolhido ou aquele sobre o qual não se tem consciência também é uma voz nos textos de pesquisa. Nesse texto, assumimos como silêncio uma proposta de análise clássica dos relatos, buscando deles extrair categorias problematizadoras para nos situarmos neste mundo. Também assumimos como intencionalmente em silêncio os participantes do GDP que não enviaram seus textos-síntese até o momento exigido para a finalização do texto. E como interpretamos esse silêncio? Uma dessas possibilidades poderia ser o não-pertencimento, afinal, os grupos se autodenominaram "Indecisos", "Caídos de Pára-quedas" (no GDP e na Educação Ambiental, mais por conta de convite para o EPEA) e outros. Também há o silêncio do grupo “Transformação em Ação", e, devido à visão crítica deste (embora essa perspectiva não fosse exclusiva deles), pode-se pensar, mas não afirmar, que o silêncio é o distanciamento de uma proposta transformadora, como a que estamos aqui narrando. Houve outro grupo, "Os Militantes", que, da mesma forma, poderia aproximar-se do silêncio de não-pertencimento e autoria dessa forma de se fazer formação. Mas é claro que de toda história se pode fazer outra.

A autoria é a marca do pesquisador, é a sua forma especial de fazer-se presente no texto, mas ela não deve ser nem muito marcada nem ausente. Essa autoria também pode referir-se aos participantes, chamandose de autoria participante aquela na qual se retorna a esses participantes para que possam verificar se os textos os retratam da forma como desejariam e se conseguem reconhecer-se neles. Este texto, como se pode perceber pelo número de autores participantes, inclui essa possibilidade.

Com relação à audiência, é importante que se pense na escrita no sentido do compartilhamento, que se pense para quem se escreve e o que é relevante para essa audiência. Considerá-la cria uma tensão/conflito, porque 
o pesquisador pode sentir que está quebrando a confiança dos participantes. Por outro lado, a escrita pode criar tensão em relação à audiência. Tendo em vista que escrevemos para pesquisadores, assumimos que este pode ser o lado de maior tensão neste texto, a considerar aspectos formais de pesquisa.

As tensões/conflitos podem envolver os três elementos. Desse modo, faz-se necessário balancear a autoria, a voz e a audiência, requerendo a atenção do pesquisador.

A forma de escrever os textos da pesquisa é outro ponto de tensão que envolve esses elementos. $\mathrm{O}$ formato que os textos adquirem decorre de um processo experimental, de tentativas, erros e acertos. Um texto narrativo precisa conter descrição, narrativa e argumentos segundo seus autores, podendo se apresentar sob diferentes e criativas formas, mas não é por esse motivo que uma pesquisa se configura como narrativa. A postura historiadora de ver e compreender o mundo e as pessoas é que a caracteriza, necessária desde seu planejamento. Pensando nisso é que apresentamos este texto como resultado de um processo de constituição de educadores ambientais.

Essa perspectiva de constituição vem sendo intensamente desenvolvida na componente curricular de Metodologia de Pesquisa Qualitativa do PPGEA - FURG, onde os significados da constituição de educadores ambientais têm sido produzidos em ambientes virtuais de aprendizagem.

E por que acreditamos nisso? Como afirma Clandinin (2006), a narrativa traz uma outra possibilidade de constituição ainda não abordada, que é a de que um sujeito que se sente oprimido frente a outras histórias pode, pela narrativa, apropriar-se desses outros sentidos e formar uma rede de fortalecimento. Ao mesmo tempo, o sujeito, ao perceber que se oprime por sua narrativa, pode, lendo as histórias, se transformar. E de tudo isso resultam outras histórias, contadas ou não, que se tornam vivências e que pela pesquisa narrativa podem ser transformadas em experiências como esta que quisemos relatar. De outra forma, poderíamos também responder à nossa pergunta trazendo novamente as palavras de Larrosa (2002, p.27) sobre o saber da experiência, nas quais o autor sublinha: 
[...] sua qualidade existencial, isto é, sua relação com a existência, com a vida singular e concreta de um existente singular e concreto. A experiência e o saber que dela deriva[m] são o que nos permite apropriar-nos de nossa própria vida. Ter uma vida própria, pessoal, como dizia Rainer Maria Rilke, em Los Cuadernos de Malthe, algo cada vez mais raro, quase tão raro quanto uma morte própria. Se chamamos existência a esta vida própria, contingente e finita, a essa vida que não está determinada por nenhuma essência nem por nenhum destino, a essa vida que não tem nenhuma razão nem nenhum fundamento fora dela mesma, a essa vida cujo sentido se vai construindo e destruindo no viver mesmo, podemos pensar que tudo o que faz impossível a experiência faz também impossível a existência.

É por isso que, ao finalizarmos este texto, entendemos que é impossível fazê-lo sem antes apresentar uma narrativa produzida naqueles dias chuvosos do IV EPEA em Rio Claro...

\section{AS IRREQUIETAS}

Cinco profissionais de origem geográfica, de histórias de vida e atuação profissional distintas, porém todas mambembes, nos encontramos e nos descobrimos iguais nas diferenças. Nossas histórias de vida - nas perspectivas pessoal, profissional e familiar, determinaram o caminho profissional, que é em essência multidisciplinar.

O desejo de descobrir, de conhecer e de agir nos permite enxergar caminhos possíveis e esse trilhar abre novas perspectivas pessoais e profissionais.

Nossa formação inicial, apesar de escolhida e necessária, nos parecia árida, técnica e insuficiente diante das inquietações e anseios. Não bastavam os conhecimentos biológicos, químicos e pedagógicos, a relação com esse conhecimento "humanizado", "naturalizado", "encantado" se fazia essencial.

A relação com o "outro", seja ele quem for ou o que for, é absolutamente necessário para o profissional em que estávamos nos transformando.

Afetos e encontros nos marcam e inquietam.

O "ensinar" a avançar, a conhecer, a libertar está sempre presente.

O estabelecimento de diálogos interpessoais, com os conhecimentos, com os saberes, com as culturas sempre foram buscados, sempre foram exercidos. Porém, saciar esses anseios, longe de trazer (além de trazer) satisfação, conduz a 
outros pontos de partida, a outras buscas de identidades pessoais, profissionais e até mesmo geográficas.

Assim nós educadoras ambientais nos formamos, na inquietude do ser e do fazer nos descobrimos, nos definimos como um sujeito educador (ambiental) irrequieto, dialógico, dinâmico e...

\section{Considerações finais}

A narrativa como constituidora de educadores ambientais e ferramenta de transformação foi a proposta assumida pelos autores. As histórias apresentadas evidenciam a paisagem dessa experiência em que educadores ambientais estiveram intervindo e produzindo histórias durante o GDP do IV EPEA.

Nesse contexto, portanto, todo o processo revelou-se promissor e foi o que nos propusemos a apresentar e descrever neste texto, juntamente com algumas características da pesquisa narrativa. Ao estudarmos as experiências dos participantes da pesquisa, refletimos sobre nossas experiências passadas e presentes e pensamos no futuro. Olhamos para nossas próprias práticas como pessoas e como profissionais, tendo em vista suas interações num contexto social. Compartilhamos os significados da pesquisa com outras pessoas, o que pode ajudar-nos a decidir sobre a linguagem que utilizamos e assim trazer outras possibilidades para recontar e compor significados diferentes. Vivermos as histórias contadas e recontadas pelos participantes favorece reflexões recíprocas e a construção de significados mais complexos sobre elas, contribuindo para a compreensão de nossas práticas em outra perspectiva, vislumbrando diferentes caminhos constituídos sempre no presente, e assim com elas passarmos a ter experiência.

\section{Referências}

BRUNER, Jerome. Making stories: law, literature, life. Harvard: Harvard University Press, 2003. 
2001.

A cultura da educação. Trad. de Marcos A. G. Domingues. Porto Alegre: Artmed,

CLANDININ, D. Jean (Ed.). Handbook of Narrative Inquiry: mapping a methodology. London: Sage Publications, 2006.

CLANDININ, D. Jean; CONNELLY, F. Michael. Narrative Inquiry. San Francisco: JosseyBass Publishers, 2000.

DEMO, Pedro. Educar pela pesquisa. Campinas: Autores Associados, 1997.

GALIAZZI, Maria do Carmo. Educar pela Pesquisa. Ijuí: Unijuí, 2003.

LARROSA, Jorge. Notas sobre a experiência e o saber da experiência. Trad. de João Wanderley Geraldi. Revista Brasileira de Educação, Rio de Janeiro, n. 19, p. 20-28, jan./abr. 2002.

Artigo recebido em 16/11/2007 - Aprovado em 06/06/2008 